\title{
Knowledge-generating activities on which technology education students draw when they design and make artefacts
}

\author{
Willem Rauscher \\ University of Pretoria, South Africa \\ willem.rauscher@up.ac.za
}

\begin{abstract}
Technology ${ }^{1}$ is often perceived simplistically as applied science, and therefore regarded as inferior to science. Scholars of technology, however, reject the view that technology is applied science and insist that technology is a cognitive system consisting of a separate body of technological knowledge. Although science is acknowledged as an important source of knowledge for technology, Vincenti (1990) identified six other knowledge-generating activities that contribute to the knowledge base in technology. These seven knowledge-generating activities were derived from an analysis of aeronautical history cases and give some insight into how engineers know what they know. However, before one can draw on Vincenti's framework of knowledge-generating activities to provide insight into how technology education students know what they know, one needs to engage with such a framework to determine its usefulness in an educational context. The purpose of this study is therefore to investigate the usefulness of Vincenti's framework, which was derived chiefly from engineering, to be able to describe how technology education students know what they know. Quantitative research was used to provide insight into the knowledge-generating activities drawn upon by education students when they design and make artefacts at the University of Pretoria. The research employed an analysis of a questionnaire administered to the students after they had finalised two different capability tasks. Findings suggest that Vincenti's framework of knowledge-generating activities is useful in technology education. The study recommends that researchers and educators deepen their understanding of how technology education students come to their technological knowledge by considering the knowledge-generating activities presented in the conceptual framework.
\end{abstract}

Keywords: knowledge-generating activities, technological knowledge, technology education, epistemology

\section{Introduction}

The starting point for many discussions in technology are the critique of the position which identifies technology with applied science (Pavlova, 2005). The phrase "science and technology" has been used so often that it creates the impression that these two learning areas must somehow be mutually inclusive. This is confirmed by Frey (1991), who notes that the link between science and technology is so commonplace that it is often assumed that they share a common methodology, symbol system (mathematics and language) and community of practitioners. Frey (1991, p. 1) states that "this misconception about the nature of science and technology and

1 The term technology will be used in the broader social science sense, where the term technology includes everything the engineer calls technology, along with engineering itself (Mitcham, 1994, p.143-144). Also, the terms technology education and technology are used interchangeably. 
about the relationship between them can be misleading at best and fatal at worst, for technology education". Educators may find that technology education is equated with science or competes with science programmes. In either case the distinctive character of technology is misunderstood (Frey, 1991).

A possible reason for this misconception might be that the epistemology has focused on science and specifically on physics. It has therefore willingly adopted the commonplace that technology is "applied science" (Ropohl, 1997). According to De Vries (1996) this view indeed formed a paradigm for the philosophy of technology for some time, and it assumes the existence of a straightforward path from scientific knowledge to the technological product. This sciencetechnology model suggests that science is the wellspring of innovation and that scientific discovery implies technological invention: technology is thus regarded as the responsive activity of applied science (Faulkner, 1994).

Recent scholars of technology, however, reject the view that technology is applied science and insist that technology is a cognitive system consisting of a separate body of technological knowledge (De Vries, 2003; 2005; Faulkner, 1994; Frey, 1991; Herschbach, 1995; Layton, 1974; Vincenti, 1990). Layton (1974), however, acknowledges the fact that technology and science might influence each other on all levels.

Vincenti (1990), providing an engineering perspective, recognises science as an important source of knowledge for technology, but also identifies six other knowledge-generating activities that contribute to the knowledge base in technology: invention, theoretical engineering research, experimental engineering research, design practice, production and direct trial. Before one can however, draw on Vincenti's framework of knowledge-generating activities to provide insight into sources of technological knowledge, one needs to engage with such a framework to determine its usefulness in a technology education context, since Vincenti derived his seven knowledge-generating activities (i.e. activities from which engineers derive their knowledge) from an analysis of aeronautical history cases. Compton (2004, p.14) emphasises that:

It is essential that we acknowledge that technology education cannot expect to "operationalise" frameworks from technology into technology education without clearly exploring the fitness of doing so ...

\section{Purpose of this study}

The purpose of this study was to investigate the usefulness of Vincenti's (1990) framework of knowledge-generating activities to technology education. One way of establishing the usefulness of Vincenti's framework, is by determining the frequency with which students engage in knowledge-generating activities during technological designing and making tasks (i.e. capability tasks). Furthermore, by determining the extent to which students draw upon knowledgegenerating activities in two content areas, one can gain insight into how knowledge is sourced in two different content areas. This can, for example, indicate if the students favour certain knowledge-generating activities in the one content area compared to the knowledge-generating activities in the other content area.

The following research questions are therefore to be addressed:

- What is the frequency of knowledge-generating activities drawn upon by education students when they design and make an artefact? 
- What is the relationship, if any, between the knowledge-generating activities drawn upon in two different content areas in technology education?

\section{Contextual background}

The study involved third year undergraduate students at the University of Pretoria, who selected technology as an elective subject as part of their four year Bachelor of Education (BEd) degree course. These students were selected because the vast majority of practising technology teachers in South Africa do not have formal training in technology education, but were generally sourced from subjects such as home economics, woodwork, metalwork and industrial arts (Van Niekerk, Ankiewicz, \& De Swart, 2010). Most current technology teachers therefore do not have the relevant academic background in terms of the technology content areas, design process and the methodological approach to technology education. In addition, most of these teachers were not trained in outcomes-based education (OBE) (Potgieter, 2004), which underpins the South African education system (DoE, 2002). Technology students at the University of Pretoria, on the other hand, are trained in technology education according to the most recent policy requirements and it is assumed that they are able to design and implement learning programmes successfully.

As part of the technology curriculum at the University of Pretoria, students have to conduct one capability task ${ }^{2}$ (project) per content area. These capability tasks are performed during noncontact time $^{3}$ (after hours, in their own time) in a constructivist manner, since each student's identified need and artefact, and therefore solution/s to the problem/s, is unique. Each student would therefore require different knowledge in different phases of the design process. This can, due to a time constraint, only be realised if the students work on their capability tasks in a constructivist manner during non-contact time. Contact time, i.e. class-time, is used only for lecturing, resource and research tasks and case studies.

This study focused on two capability tasks from two different content areas in the third year design and technology education curriculum. The modules involved were JOT 353 and JOT 354.

\section{Module JOT 353}

JOT 353 deals with the content area of systems and control in leaning outcome 2 . It is a sevenweek $^{4}$ module offered during the third term. The capability task in this module requires students to design and make an educational toy comprising at least two different mechanical components (e.g. gears, pulleys, levers, etc.), and an electrical circuit. At the end of the module the educational toy together with a comprehensive project portfolio were assessed. Figures 1 and 2 are examples of students' educational toys.

2 Capability tasks involve projects that require students to design and make a product that works (Barlex, 2000). These projects are conducted over a long period of time using the design process, i.e. investigating, designing, making, evaluating and communicating, as prescribed by the Department of Education (2003).

3 It is assumed that all the third year design and technology students, although they may have had no previous engagement in the content of systems and control, and structures, are sufficiently competent to follow the design process independently as it formed part of their formal first and second year training.

$4 \quad$ There are four 50 minutes periods per week. 


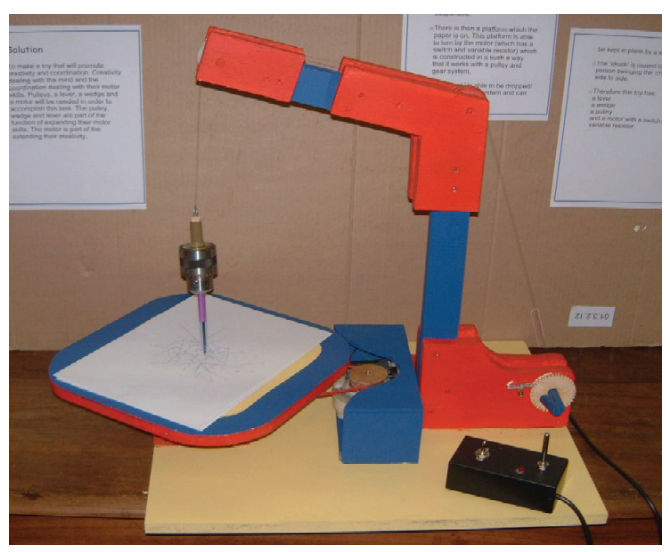

Figure 1: $\quad$ Educational toy 1

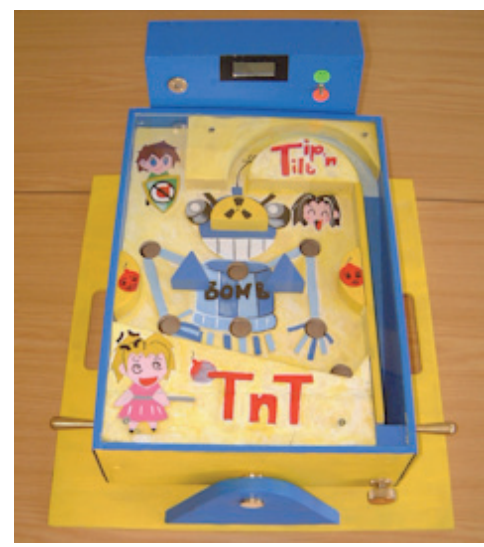

Figure 2: $\quad$ Educational toy 2

Figure 1 depicts a drawing toy. A motor turns a platform on which a sheet of paper is placed. The player can swing the pen attached to a pendulum, which results in a drawing. Provision was made for motor speed control and the purpose of this toy is to incorporate an element of fun into a drawing activity.

The toy shown in figure 2 is based on the principle of a pinball machine. After a metal ball is propelled upwards by a spring (bottom right), the ball will roll downwards again, because the main body of the toy was constructed an inclined angle. The player then uses the two handles on the side to manipulate the ball into one of the holes. A timer (top front) is used determine the time taken by each player to achieve this gaol. The educational value of this game is that it improves hand /eye coordination.

\section{Module JOT 354}

JOT 354 deals with the content area of structures in leaning outcome 2 . This is another sevenweek module, which is offered during the fourth term. In this module, students were free to choose their own project which they had to derive from the assessment standards, for the grade of their choice, specified in the Revised National Curriculum Statement (RNCS) for technology (Department of Education, 2002). They then had to design and make the artefact as a capability task. At the end of the module both the structure artefact as well the project portfolio were assessed for a mark. Figures 3 and 4 are examples of the students' structure artefacts. 


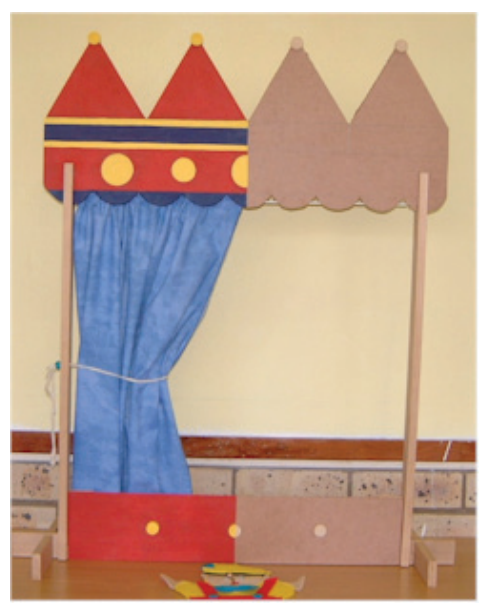

Figure 3: $\quad$ Structure 1

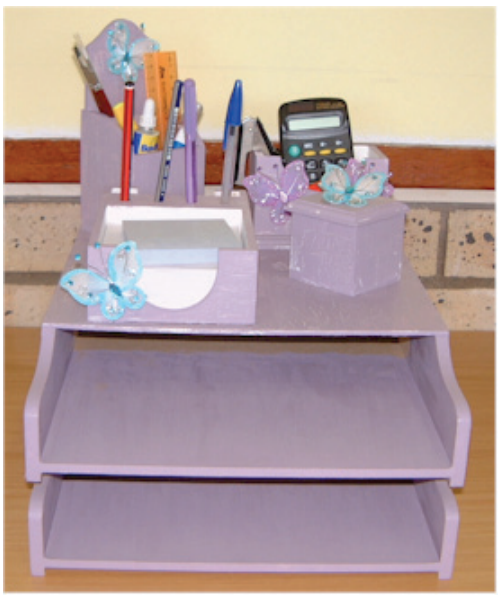

Figure 4: $\quad$ Structure 2

Figure 3 is a photograph of a puppet theatre, which was conceptualised to address the assessment standards of structures for grade 7. The puppet theatre was made from wood and plywood and the focus of this capability task was mainly on joining techniques and stability (e.g. base size and centre of gravity).

Figure 4 depicts a stationery holder, which was conceptualised to address the assessment standards of structures for grade 5. This structure was made mainly from plywood and the focus of this capability task was on different types of structures (e.g. frame and shell), and on the relationship between materials and the load a structure of a product can support.

\section{Conceptual framework}

The conceptual framework of this study is based on Vincenti's (1990) knowledge-generating activities which were derived from an analysis of aeronautical history cases. Table 1 shows these knowledge-generating activities and also provides a brief description of each. 
Table 1: Conceptual framework based on Vincenti's (1990, p.229-234) knowledge-generating activities

\begin{tabular}{|c|c|}
\hline $\begin{array}{l}\text { Knowledge- } \\
\text { generating } \\
\text { activity }\end{array}$ & Brief description of the knowledge-generating activity \\
\hline $\begin{array}{l}\text { Transfer from } \\
\text { science }\end{array}$ & $\begin{array}{l}\text { A transfer of knowledge from theoretical science often entails } \\
\text { reformulation or adaptation to make the knowledge useful to engineers. } \\
\text { This does not, however, mean that science is the sole or major source or } \\
\text { that engineering can be regarded as applied science. }\end{array}$ \\
\hline Invention & $\begin{array}{l}\text { Invention is a source of the operational principles and normal } \\
\text { configurations that underlie normal design. Contriving such fundamental } \\
\text { concepts is by definition an act of invention even if one comes upon them } \\
\text { by chance. It is an elusive and creative enterprise that produces these } \\
\text { fundamental concepts. }\end{array}$ \\
\hline $\begin{array}{l}\text { Theoretical } \\
\text { engineering } \\
\text { research }\end{array}$ & $\begin{array}{l}\text { Theoretical engineering research entails knowledge produced by engineers } \\
\text { through theoretical activity, mostly in academic institutions and research } \\
\text { laboratories. Theoretical research in engineering has much in common with } \\
\text { theoretical research in science, as both are systematic and conceptually } \\
\text { demanding, and often mathematically complex. Differences are } \\
\text { embedded in the goals, aims, priorities, attitudes, etc. of the research. }\end{array}$ \\
\hline $\begin{array}{l}\text { Experimental } \\
\text { engineering } \\
\text { research }\end{array}$ & $\begin{array}{l}\text { Experimental engineering research is a major source of quantitative data } \\
\text { and requires special test facilities, experimental techniques, measuring } \\
\text { devices, etc. Since quantitative data of some kind is essential to design } \\
\text { in any field, so also is the experimental research from which it stems. } \\
\text { Experimental research provides more than design data, as it also produces } \\
\text { analytical concepts and ways of thinking. }\end{array}$ \\
\hline $\begin{array}{l}\text { Design } \\
\text { practice }\end{array}$ & $\begin{array}{l}\text { Day-to-day design practice not only makes use of engineering knowledge, } \\
\text { but also contributes to it. Contributions to fundamental design concepts, } \\
\text { theoretical tools and quantitative data are indirect, e.g. practice reveals } \\
\text { problems and needs that demand research in order to generate such } \\
\text { knowledge, while contributions to criteria and specifications, practical } \\
\text { considerations, and design instrumentalities are more direct, e.g. a design } \\
\text { criterion of general applicability. }\end{array}$ \\
\hline Production & $\begin{array}{l}\text { Production is another source of design knowledge and can, for example, } \\
\text { reveal that a material is too thin and too large, which can lead to cracking, } \\
\text { or it can reveal that a machine is too large, which limits the operating } \\
\text { space on the floor. This kind of knowledge contributes to the category of } \\
\text { practical considerations. Production experience can also contribute to, for } \\
\text { example, the formulation of tables of thickness of sheets suitable to use } \\
\text { with rivets of varying sizes in different types of flush riveting (quantitative } \\
\text { data). }\end{array}$ \\
\hline
\end{tabular}


Direct trial is related to testing. Engineers normally test the devices they design. Likewise, consumers who buy these devices put them to use in everyday life. Both kinds of direct trial provide design knowledge. If the device falls short in any of the tests, recommendations can be made to correct the shortcomings or offer suggestions for redesign. Similarly, customers can provide feedback about the everyday operation of these devices. Do the devices, for example, live up to their expectations and are these the results they envisaged when they bought the devices?

The motivation for selecting Vincenti's (1990) framework, presented in table 1, was that it seems to be the most complete one (Broens \& De Vries, 2003). It should be noted, however that Vincenti's (1990) framework has limitations: he admits that the knowledge-generating activities are not mutually exclusive and it is therefore possible that more than one activity, e.g. research and invention, can take place to generate an item of knowledge. In addition, Vincenti acknowledges that the framework is not entirely exhaustive: although the major activities are presumably complete, the subspecies within them most likely are not.

\section{Methodology}

\section{Design of the study}

Quantitative research was used to provide insight into the knowledge-generating activities drawn upon by education students when they designed and made artefacts. This study engaged a correlation design to determine the relationship between the knowledge-generating activities drawn upon in two different content areas in technology education. By determining the relationship between the extent to which students draw upon knowledge-generating activities in two content areas, one can gain insight into the way various knowledge-generating activities are sourced in two different content areas.

\section{Instrument, reliability and validity}

A rating scale questionnaire was administered at the end of each module to collect data. The students had to indicate the extent to which they had drawn upon the knowledge-generating activities when they designed and made artefacts by selecting from the following options: "Not at all"; "To a limited extent"; "To a fairly large extent"; and "Extensively".

The questionnaire was piloted before it was administered, using the same group of students. When the questionnaire was found to be too complex, it was simplified. Questions were more simply formulated and short descriptions from Vincenti's (1990) book were added to explain the concepts. The revised questionnaire was then re-tested on five students who were initially involved in the pilot study in an informal interview-like situation. This time around, they reported that they found the revised questionnaire easier to complete. The students' understanding of the questions and concepts were also tested during the informal interview-like situation by asking probing questions not previously included in the questionnaire. From their answers it seemed that they understood the questions and terminology. 
Truthfulness was established by means of content validity and was achieved by deriving the questions for the questionnaire directly from all the categories of knowledge listed in the conceptual framework.

\section{Sampling}

The sample was a non-random convenient sample. It consisted of two groups of students: the first group of 22 students was part of the JOT 353 (systems and control) module and the second group of 21 students was part of the JOT 354 (structures) module. Both groups were heterogeneous in terms of language, gender and culture, and ranged in age from 20-23.

Most of the students were present in both modules. Students who were repeating either or both of the modules accounted for the slight difference in student numbers between the two modules.

\section{Research limitations}

The limitations acknowledged by this researcher include:

- in regard to the scope of this study, which was conducted using one group of undergraduate students from one university only, who selected technology education as an elective subject;

- only a limited number of students participated in the research. This is a limitation, since it restricts the possibility of making quantitative generalisations;

- the samples were not identical, since not all the students were present in both modules. This could have resulted in experimental mortality (Neuman, 2006), and is therefore a limitation of this study; and

- it is accepted that the activities that were performed during contact time had an influence on the way students engaged in technological knowledge when they conducted the capability tasks. It is, however, a limitation of this study that it was not possible to determine the extent of this influence, since the students did not explicitly indicate what knowledge was acquired by themselves or by means of the classroom activities.

\section{Results and discussion}

The questionnaire was administered at the end of each module. It consisted of rating scale questions which required students to indicate the extent to which they made use of the knowledgegenerating activities to design and make an artefact. The results of the students' responses to the rating scale questions, indicating the extent to which they drew knowledge from the knowledgegenerating activities to design and make an educational toy, are shown in figure 5. 


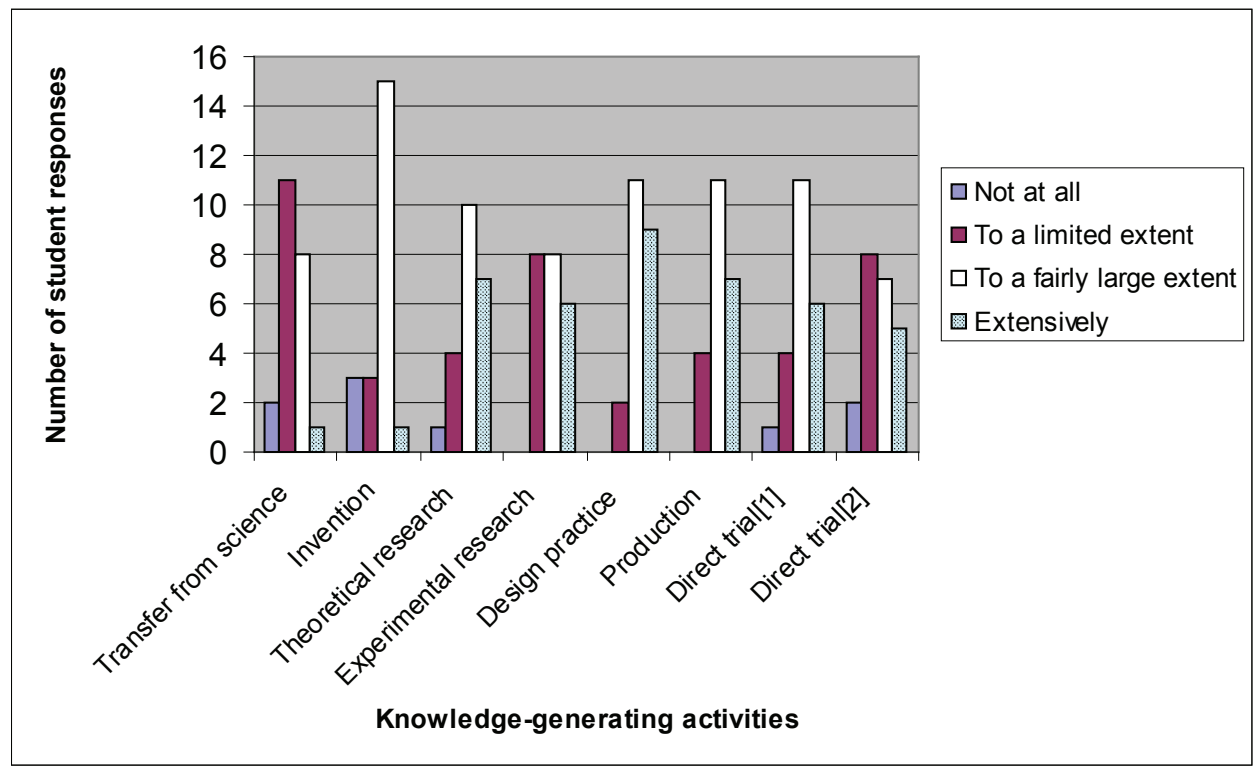

Figure 5: Number of student responses to the knowledge-generating activities relevant to the educational toy $(\mathrm{N}=22)$

Figure 5 shows that the students indicated that they drew predominantly "to a fairly large extent" from six of the eight (75\%) knowledge-generating activities during the educational toy capability task. The high level of student responses to this scale suggests that Vincenti's (1990) knowledgegenerating activities were useful to this capability task.

Two knowledge-generating activities peaked at the "to a limited extent" scale, i.e. transfer from science (selected by 11 out of 22 students) and direct trial [2] (selected by 8 out of 22 students). A possible reason for the students' reluctance to transfer more knowledge from science, might be the problem related to transfer, i.e. learners find it difficult (or impossible) to transfer knowledge successfully from one context (e.g. the science classroom) to another (e.g. the technology classroom) (De Corte, 1999; Hatano \& Greeno, 1999; Stark, Mandl, Gruber, \& Renk1, 1999). Another possible reason why the students overlooked the influence of science in technology is that technology education is often perceived by both teachers and students to be somewhat distant from science education.

5 For the purpose of this study it was decided to differentiate between two kinds of direct trial:

[1] Question: To what extent did you evaluate (test) your artefact in order to determine whether it does what it was designed to do?

[2] Question: To what extent did you use the knowledge acquired about the artefact's shortcomings during the direct trial to improve the design or at least make suggestions to improve the design?

The reason for making this distinction was to investigate whether the students, once they have determined through testing the shortcomings of their artefacts, actually implement the necessary improvements. 
The second part of direct trial [2], which peaked at the "to a limited extent" scale, explored the extent to which the students used the knowledge acquired about the artefact's shortcomings during the direct trial to improve the design, or at least make suggestions to improve the design. Although most of the students did make suggestions for improvements after they had tested the artefact during the evaluation phase of the design process (as stipulated in the RNCS for technology), few went so far as to actually improve the artefact. The students claimed that they ran out of time at the end of the module, although laziness might be the real reason they did not make improvements.

The results of student responses to the rating scale questions that indicate the extent to which they drew knowledge from the knowledge-generating activities to design and make a structure artefact, are shown in Figure 6.

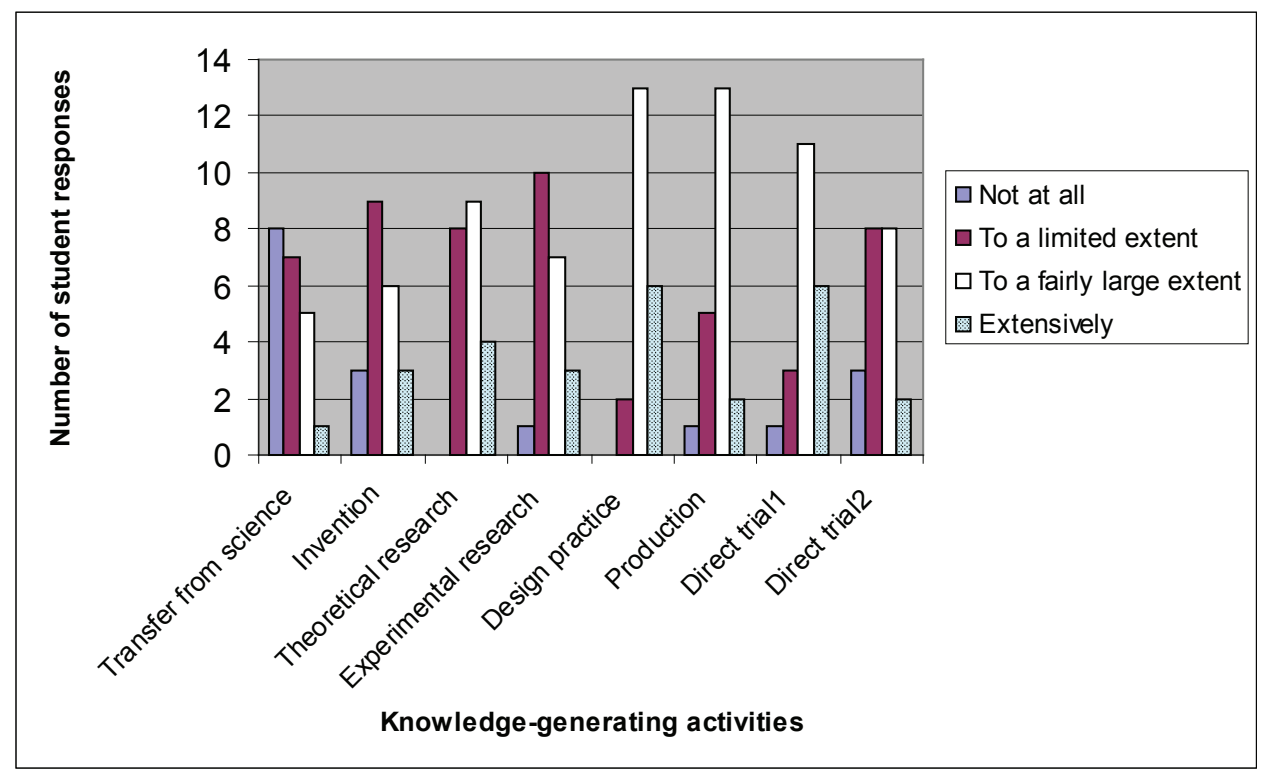

Figure 6: Number of student responses to the knowledge-generating activities relevant to the structure artefact $(\mathrm{N}=21)$

Figure 6 shows that the students indicated that they drew predominantly "to a fairly large extent" from five of the eight $(63 \%)$ knowledge-generating activities during the structures capability task. The fairly high level of student responses to this scale suggests that Vincenti's (1990) knowledge-generating activities were also relevant to this capability task.

One knowledge-generating activity, namely transfer from science, peaked (selected by 8 out of 21 students) at the "not at all" scale. In addition to the suggestion earlier, discussed in the section on the educational toy, as to why students did not transfer more knowledge from science, it is surmised that it may be as a result of the fact that not all the students who selected technology as an elective also selected science as an elective. Only about half the students in the technology class also specialise in science at university level. All the students should, however, have a basic background in science, since it is a compulsory learning area up to grade 9 . It is therefore 
disappointing that transfer from science, even on an elementary level, did not occur to a greater extent, because scientific knowledge is an important contributor to engineering knowledge (Layton, 1971; Vincenti, 1990).

From the foregoing it seems that the knowledge-generating activities derived from professional engineering are useful to technology education, as can be seen from the high extent to which the students drew from most of the knowledge-generating activities in both content areas.

\section{Relationship in the knowledge-generating activities between the two content areas}

The Pearson product moment correlation coefficient ( $r$ ) was used to establish whether a relationship exists in the extent to which students have made use of the knowledge-generating activities between the two content areas. Table 2 shows the Pearson's $r$ for each knowledgegenerating activity.

Table 2: The relationship between the two content areas

\begin{tabular}{|l|l|}
\hline Knowledge-generating activities & $\mathbf{R}$ \\
\hline Transfer from science & +.42 \\
\hline Invention & +.24 \\
\hline Theoretical research & +.72 \\
\hline Experimental research & +.84 \\
\hline Design practice & +.93 \\
\hline Production & +.81 \\
\hline Direct trial $^{1}$ & +.99 \\
\hline Direct trial $^{2}$ & +.81 \\
\hline
\end{tabular}

For a study involving 22 students, $\left(\mathrm{df}^{6}=20\right)$, a coefficient of .54 is needed to be significant at the .01 level (Ary, Jacobs, \& Razavieh, 2002:361,548). Six of the eight relationships shown in table 2 were statistically significant at the .01 level since their $r$ values are higher than .54 and these relationships are less likely to be a function of chance, since there is only a 1 in 100 possibility of chance.

One relationship (for the knowledge-generating activity pertaining to transfer from science) is significant at the .05 level with an $\mathrm{r}$ value of .42 . This relationship is therefore also statistically significant with only a 5 in 100 possibility of chance.

One relationship for the knowledge-generating activity pertaining to invention is not significant at the .10 level with its $r$ value of .24 , and this relationship has a higher probability to be a function of chance than the other seven relationships shown in table 2.

Jackson's (2006) estimates were used to interpret the above-mentioned (table 2) Pearson productmoment correlation coefficient. Table 3 lists the estimates.

$6 \mathrm{df}=\mathrm{N}-1$ 
Table 3: Estimates for weak, moderate and strong correlation coefficients (Jackson, 2006:124)

\begin{tabular}{|l|l|}
\hline Correlation coefficient & Strength of relationship \\
\hline $\pm .70-1.00$ & Strong \\
\hline $\pm .30-.69$ & Moderate \\
\hline $\pm .00-.29$ & None $(.00)$ to weak \\
\hline
\end{tabular}

Five of the seven knowledge-generating activities (direct trial counts as one activity only) show a strong positive relationship between the two content areas (according to table 3 ). This means that the students have drawn knowledge from these knowledge-generating activities to nearly the same extent in both the content areas. Transfer from science shows a moderate positive relationship $(\mathrm{r}=+.42)$ and invention shows a weak positive relationship $(\mathrm{r}=+.24)$ between the two content areas. A possible reason for the weak positive relationship pertaining to invention is that the educational toy presented the challenge of learning mostly "new" concepts (especially the electrical/electronic systems and control section, of which the students had little or no prior knowledge), compared to the mostly familiar concepts in structures for which they chose simple projects. It is therefore understandable that the students, with their limited experience, could easily have thought that they had invented new concepts during the educational toy task, compared to the structures artefact task.

\section{Conclusion}

The results from this study show that the highest number of students selected the "to a fairly large extent" scale in the knowledge-generating activities section for six of the seven knowledgegenerating activities in the design and making of the educational toy. Transfer from science received the highest number of responses on the "to a limited extent" scale.

For the structural artefact, the highest number of students selected the "to a fairly large extent" scale in four of the seven knowledge-generating activities. Invention and experimental research received the highest number of responses on the "to a limited extent" scale, while transfer from science received the most responses to the "not at all" scale.

The high level of student engagement in most of the knowledge-generating activities in both content areas seems to indicate that the conceptual framework chiefly derived from and used by professional engineers, is useful to technology education. One important aspect in the 'usefulness' of the framework is that it can, for example, be used as a means to develop assignments in such a way that it requires students to draw from the whole spectrum of knowledge-generating activities. Another use of the framework is that it seems to be able to distinguish between two capability tasks, showing how they differ with regard to the knowledge-generating activities from which students drew. This is important if one wants to use the framework to determine whether one course is better in utilising the full spectrum of knowledge-generating activities than another.

The study recommends that researchers and educators deepen their understanding of how technology education students know what they know by considering the knowledge-generating activities presented in the conceptual framework. 


\section{References}

Ary, D., Jacobs, L.C., \& Razavieh, A. (2002). Introduction to research in education. Belmont: Wadsworth/ Thomson learning.

Barlex, D. (2000). Perspectives on departmental organisation and children's learning through the Nuffield design and technology project. In J. Eggleston (Ed.), Teaching and learning design and technology (pp. 91-103). London: Continuum.

Broens, R.C.J., \& De Vries, M. J. (2003). Classifying technological knowledge for presentation to mechanical engineering designers. Design Studies, 24(5), 457-471.

Compton, V. (2004). Technological knowledge: A developing framework for technology education in New Zealand (Briefing paper prepared for the New Zealand Ministry of Education Curriculum Project).

De Corte, E. (1999). On the road to transfer: An introduction. International Journal of Educational Research, 31(7), 555-559.

De Vries, M.J. (1996). Technology education: Beyond the "technology is applied science" paradigm. Journal of Technology Education, 8(1), 7-15.

De Vries, M.J. (2003). The nature of technological knowledge: Extending empirically informed studies into what engineers know. Techné: Research in Philosophy and Technology, 6(3), 1-21.

De Vries, M.J. (2005). The nature of technological knowledge: Philosophical reflections and educational consequences. International Journal of Technology and Design Education, 15(2), 149-154.

Department of Education. (2002). Revised National Curriculum Statement for Grades R-9 (Schools) for Technology. Pretoria: Department of Education.

Department of Education. (2003). Revised National Curriculum Statement Grades R-9 (Schools): Teacher's guide for the development of learning programmes - Technology. Pretoria: Department of Education.

Faulkner, W. (1994). Conceptualizing knowledge used in innovation: A second look at the sciencetechnology distinction and industrial innovation. Science, Technology, \& Human Values, 19(4), 425458.

Frey, R.E. (1991). Another look at technology and science. Journal of Technology Education, 3(1), 1-12.

Hatano, G., \& Greeno, J.G. (1999). Commentary: Alternative perspectives on transfer and transfer studies. International Journal of Educational Research, 31(7), 645-654.

Herschbach, D.R. (1995). Technology as knowledge: Implications for instruction. Journal of Technology Education, 7(1), 31-42.

Jackson, S.L. (2006). Research methods and statistics: A critical thinking approach. Singapore: Thomson Wadsworth.

Layton, E.T. (1971). Mirror-image twins: The communities of science and technology in 19th-century America. Technology and Culture, 12(4), 562-580.

Layton, E.T. (1974). Technology as knowledge. Technology and Culture, 15(1), 31-41.

Mitcham, C. (1994). Thinking through technology. Chicago: The University of Chicago Press.

Neuman, W.L. (2006). Social research methods: Qualitative and quantitative approaches. Boston: Pearson.

Pavlova, M. (2005). Knowledge and values in technology education. International Journal of Technology and Design Education, 15(2), 127-147. 
Potgieter, C. (2004). The impact of the implementation of technology education on in-service teacher education in South Africa (impact of technology education in the RSA). International Journal of Technology and Design Education, 14(3), 205-218.

Ropohl, G. (1997). Knowledge types in technology. International Journal of Technology and Design Education, 7(1-2), 65-72.

Stark, R., Mandl, H., Gruber, H., \& Renkl, A. (1999). Instructional means to overcome transfer problems in the domain of economics: Empirical studies. International Journal of Educational Research, 31(7), 591-609.

Van Niekerk, E., Ankiewicz, P., \& De Swart, E. (2010). A process-based assessment framework for technology education: A case study. International Journal of Technology and Design Education, 20(2), 191-216

Vincenti, W.G. (1990). What engineers know and how they know it. Baltimore/London: Johns Hopkins University Press. 